Table 2

Effects of Potassium on Physiological Parameters When Steers Were Injected Intraruminally with Either Water or Potassium Solution and Then Fed a Ration Containing 0.6\% Potassium

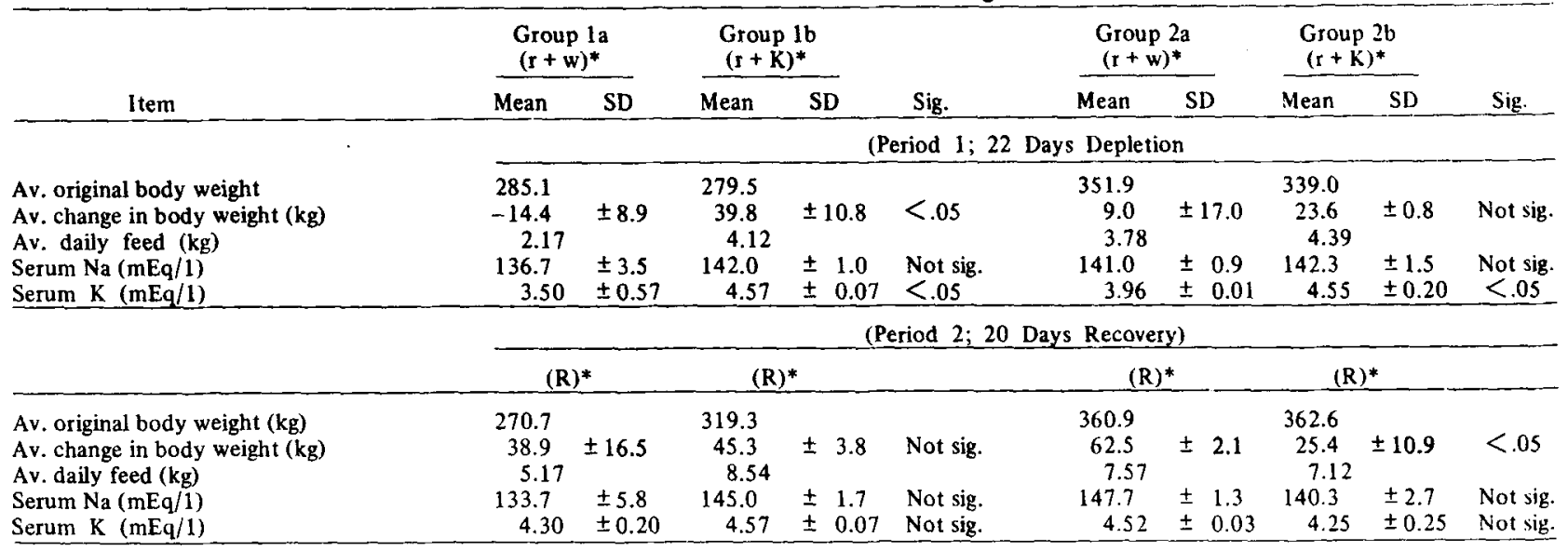

Groups $1 a$ and $l b$ were initially in a lower physiological plane of body potassium than Groups $2 a$ and $2 b$

* Injections: $W$, water; $K$, potassium; Ration potassium: $r, 0.25 \% ; R, 0.60 \%$

omitted from the ration, the rats displayed poor appetite and did not gain weight. The results of the recovery period suggested that for the management of the natural consummatory behavior gustatory and olfactory cues are important. They probably are crucial for discrimination between rations deficient or adequate in potassium under natural conditions.

Throughout this study, serum potassium concentrations reflected the potassium status of the animals. In general, the data suggested that the extent of ration consumption depended upon adequate quantities of potassium entering the rumen either orally or via intraruminal injection. This suggests that the potassium effect of feed consumption is probably directly related to changes in blood potassium. It is likely that a change in potassium concentration of the arterial blood perfusing the taste buds is, in some way, responsible for the effect of potassium on modulating feed consumption. Further research will be required to establish the role of changes in blood potassium on feed consumption.

\section{REFERENCES}

CAMPBELI, L. D. Potassium metabolism in the ovine. MS thesis, University of Manitoba, 1964.

CANNON, P. R., FRAZIER, L. E., \& HUGHES, $R$. H. Influence of potassium on tissue prote in synthesis. Metabolism, 1952, 1, 49-57.

DEVLIN, T. J., ROBERTS, W. K., \& St. Omer, V. V. E. Effects of dietary potassium upon growth serum electrolytes and intrarumen environment of finishing beef steers. Joumal of Animal Science, 1969, 28, 557-562.

MILNER, P., \& ZUCKER, I. Specific hunger for potassium in the rat. Psychonomic Science, $1965,2,17-18$.

RICHTER, C. P. Total self-regulatory functions in animals and human beings. Harvey Lectures, 1942, 38, 63-103.
STEEL, R. G. D., \& TORRIE, J. H. Principles and procedures of statistics. New York: McGraw-Hill, 1960.

St. OMER, V. V. E. The role of potassium in bovine nutrition. MS thesis, University of Manitoba, 1965.

St. OMER, V. V. E., \& ROBERTS, W. K. Some effects of dietary potassium upon digestibility, serum electrolytes and utilization of potassium, sodium, nitrogen and water in heifers. Canadian Journal of Animal Science, $1967,47,39-46$.
WELT, L. G., HOLLANDER, JR., W. \& BLYTHE, W. The consequences of potassium depletion. Journal of Chronic Diseases, 1960 , $11,213-254$.

\section{NOTES}

1. Supported in part by NRC (Canada) grant and Horned Cattle Purchase Fund, Manitoba Department of Agriculture and Conservation.

2. Present address: Bureau of Child Research, Parsons State Hospital, Parsons, Kans. 67357.

3. Present address: E. S. Erwin and Associates, Tolleson, Ariz. 85353.

\title{
Time-dependent memory storage: An alternative interpretation of some data ${ }^{1}$
}

ROBERT M. ADAMS ${ }^{2}$ and WILLIAM $H$. CALHOUN, University of Tennessee, Knoxville, Tenn. 37916

Mice were administered a single-shock trial on a step-down apparatus. For half the animals, step-down latency was again determined at selected times following shock; for the other half, activity level was measured at comparable times. For both step-down latency and activity level, there was a systematic relation between the measure and time-following-shock. Further, these two measures were inversely related. This latter result indicates that step-down performance and activity covary and are possibly related to a single organismic other-than-memory variable. 
Fig. 1. Retention and activity measures as a function of time-following-shock.

Recent experiments with one-trial response-suppression tasks have tested animals for retention at varying intervals following the learning trial. The curve for retention plotted against intertrial interval (ITI) has been interpreted as demonstrating, at least in part, time-dependent memory storage processes or consolidation of the learning experience (e.g., Irwin et al, 1964; McGaugh, 1966). The question to be raised here is whether or not such performance variations necessarily require the postulation of a dynamic memory process.

The response typically used in these tasks is a simple locomotor response highly dependent on the general activity level of the animal (the more active the animal, the more likely it is to enter a hole or step off a platform). If it could be shown that activity is high at ITIs where retention is low, and vice versa, the results of several previous studies could be interpreted more parsimoniously. Electric shock is an unusual event in the life of a colony-raised mouse, and its effects may be more significant as a behavior-controller than changes in endogenous electrical or chemical activity in the CNS. The present study will attempt to examine behavior changes as a function of time-following-shock as a partial test of this proposition.

\section{SUBJECTS}

The Ss were 150 male ICR mice, approximately 90 days of age, and housed in groups of 12 prior to the experiment, with ad lib food and water.

\section{APPRATUS}

The "learning" apparatus, previously described in Calhoun \& Murphy (1966), was a step-off device similar to that described by Essman \& Alpern (1964). A circular platform, $7.6 \mathrm{~cm}$ in diam, could be lowered from $20.3 \mathrm{~cm}$ above a large platform to within $1.27 \mathrm{~cm}$ of the lower platform. The area was lighted from $61 \mathrm{~cm}$ above by a $40-W$ bulb. The shock source was an Applegate constant-current stimulator, Model 228. Latency of the step-off response was measured by a Standard electric timer. Maximum shock duration $(1.0 \mathrm{sec})$ was controlled by a Hunter Series D timer.

The activity apparatus was a photocell cage. The $S$ was placed in a $15 \times 15 \mathrm{~cm}$ Plexiglas box, with a hardware-cloth floor. Two light beams from Lafayette PC-45 sources divided the compartment into four equal parts. When either beam was broken,

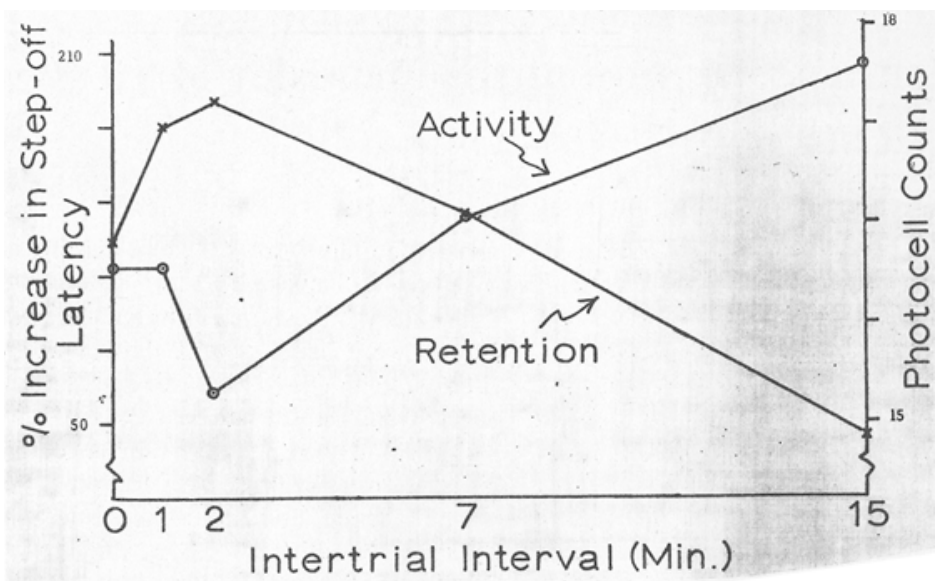

a Knight photocell relay was activated and registered a count automatically. PROCEDURE

The Ss were divided randomly into two groups designated activity and retention. Both groups were given identical treatment on Trial 1, the "learning" trial. For this trial, $S$ was placed on the smaller platform at the fully raised position. The platform was lowered slowly by hand. When the platform reached the fully lowered position, a timer started automatically. When $S$ stepped to the lower platform (defined as placing both front feet down), the closing of a switch delivered a $0.4-\mathrm{mA}$ footshock and stopped the timer. The shock was terminated when the mouse broke contact between the upper and lower platforms or after $1.0 \mathrm{sec}$. Trial 1 latency, therefore was defined as the time between the platform's reaching its lowest position and the onset of shock. (Two Ss jumped before the platform reached its lowest position and were therefore discarded.) The $\mathbf{S}$ was then removed from the learning apparatus and placed in a small wire-screen cage to await Trial 2. The exception was the group given Trial 2 immediately (see below).

The Ss within each group were then further divided randomly into five subgroups, differing on length of the interval between Trials 1 and 2 . These ITIs were $0,1,2,7$, and $15 \mathrm{~min}$. The Ss of the retention group, after the appropriate ITI, were returned to the step-down apparatus for a second trial to test for suppression of the step-off response. Trial 2 was identical to Trial 1 except that no shock was given. The Ss of the activity group, after appropriate interval, were placed in the photocell box, and activity was recorded for a 30 -sec period. Handling throughout the study was minimal, and Ss were always lifted by the tail.

\section{RESULTS AND DISCUSSION}

There are several possible measures to use in assessing retention of the shock experience. For example, Irwin et al (1964) used average Trial 2 latency, while McGaugh (1966) reported the per cent of animals that exceeded some predetermined latency on the second trial. The retention measure chosen for use with these data was per cent change in latency from Trial 1 to Trial 2. This measure was considered to be a sensitive one, serving to adjust for variability in Trial 1 latency, and making use of all the available data on each $S$.

Figure 1 shows both retention and activity measures as a function of ITI. The increase in retention over the first $2 \mathrm{~min}$ is accompanied by a decline in activity. The following decline in retention is accompanied by an increase in activity.

The results offer support for the argument that activity (as measured in a photocell box) is a variable to be considered carefully in interpreting retention curves. The results support the contention that there are factors not related to consolidation that influence retention curves. In this study, a simple variable, activity level, seems to account for the variation in step-down latency at Trial 2.

\section{REFERENCES}

CALHOUN, w. H., \& MURPHY, R. J. Pre- and post-trial stimulation: Effects on retention. Psychonomic Science, 1966, 5, 435-436.

ESSMAN, W. B., \& ALPERN, H. Single trial conditioning: Methodology and results with mice. Psychological Reports, 1964, 14, 731-740.

IRWIN, S., KALSNER, S., \& CURTIS, A. Direct demonstration of consolidation of one-trial learning. Federation Proceedings, 1964, 23 (No. 2), 102 (Abstract).

McGAUGH, J. L. Time-dependent processes in memory storage. Science, 1966, 153, 1351-1358.

\section{NOTES}

1. In part supported by NIMH Grant No. MH12770. These results were presented at the Southeastern Psychological Association annual meeting, Atlanta, 1967.

2. Present address: Department of Psychology, Fort Hays Kansas State College, Hays, Kans. 67601 